\title{
Effects of monobutyrin and tributyrin on liver lipid profile, caecal microbiota composition and SCFA in high-fat diet-fed rats
}

\author{
Thao Duy Nguyen*, Olena Prykhodko, Frida Fåk Hållenius and Margareta Nyman \\ Food for Health Science Centre, Lund University, PO Box 124, SE-221 00, Lund, Sweden
}

(Received 9 May 2017 - Final revision received 11 July 2017 - Accepted 2 August 2017)

Journal of Nutritional Science (2017), vol. 6, e51, page 1 of 14

doi:10.1017/jns.2017.54

Abstract

Butyric acid has been shown to have suppressive effects on inflammation and diseases related to the intestinal tract. The aim of the present study was to investigate whether supplementation of two glycerol esters, monobutyrin (MB) and tributyrin (TB), would reach the hindgut of rats, thus having an effect on the caecal profile of SCFA, microbiota composition and some risk markers associated with chronic inflammation. For this purpose, rats were fed highfat diets after adding MB (1 and $5 \mathrm{~g} / \mathrm{kg}$ ) and TB $(5 \mathrm{~g} / \mathrm{kg})$ to a diet without any supplementation (high-fat control; HFC). A low-fat (LF) diet was also included. In the liver, total cholesterol concentrations, LDL-cholesterol concentrations, LDL:HDL ratio, and succinic acid concentrations were reduced in rats given the MB and TB $(5 \mathrm{~g} / \mathrm{kg})$ diets, compared with the group fed the HFC diet. These effects were more pronounced in MB than TB groups as also expressed by down-regulation of the gene Cyp8b1. The composition of the caecal microbiota in rats fed MB and TB was separated from the group fed the HFC diet, and also the LF diet, as evidenced by the absence of the phylum TM7 and reduced abundance of the genera Dorea (similar to LF-fed rats) and r 4 -4. Notably, the caecal abundance of Mucispirillum was markedly increased in the MB group compared with the HFC group. The results suggest that dietary supplementation of MB and TB can be used to counteract disturbances associated with a HFC diet, by altering the gut microbiota, and decreasing liver lipids and succinic acid concentrations.

Key words: SCFA: Succinic acid: Gut microbiota: Liver cholesterol: Bile acid-related genes

During recent years, it has become more and more evident that the colonic environment is of crucial importance for both colonic and metabolic health. For instance, inflammation, which is a common denominator observed in the onset of diseases, is mediated via the colon by microbiota products. A diet high in fat is thought to have a direct effect on obesity-related inflammation by altering the gut microbiota composition and increasing intestinal permeability, together with increased lipopolysaccharide (LPS) release into the systemic circulation ${ }^{(1-3)}$. Lipopolysaccharide-binding protein (LBP) binds to LPS, and has been suggested as a biomarker of $\operatorname{LPS}^{(4,5)}$. Especially, a high fat intake changes the SCFA formation to lower proportions of butyric acid and higher of succinic acid, an intermediary colonic metabolite classically known as a precursor of propionic $\operatorname{acid}^{(6)}$, as shown in rats in several studies ${ }^{(7,8)}$. Furthermore, high amounts of succinic acid may be formed at a low bacterial activity in the colon caused by antibiotic treatment ${ }^{(9)}$; and succinic acid concentration has been shown to correlate with the severity of caecal inflammation in a mouse model of ulcerative colitis ${ }^{(10)}$. Taken together, an impaired gut health initiated by an imbalanced microbiota composition can be the origin of both colonic and metabolic diseases, apparently highlighting a protective role of SCFA.

SCFA are the main products of fermentation of indigestible carbohydrates by the gut microbiota ${ }^{(11)}$. Besides their traditional role as an energy source for colonocytes, SCFA are well known for their potent anti-inflammatory function. For example, butyrate has been shown to suppress production of

Abbreviations: HFC, high-fat control; LBP, lipopolysaccharide-binding protein; LF, low-fat; LPS, lipopolysaccharide; MB, monobutyrin; TB, tributyrin.

* Corresponding author: T. D. Nguyen, fax +46 46222 4532, email thao.nguyen@food-health-science.lu.se

(C) The Author(s) 2017. This is an Open Access article, distributed under the terms of the Creative Commons Attribution licence (http://creativecommons.org/licenses/by/4.0/), which permits unrestricted reuse, distribution, and reproduction in any medium, provided the original work is properly cited. 
pro-inflammatory molecules via inhibition of inflammatory pathways $^{(12,13)}$. The importance of butyrate for maintaining colonic health has been shown in a number of studies in both human subjects and rats with butyrylated resistant starch (high-amylose starch acetylated with butyrate), which delivers butyric acid in physiologically effective concentrations to the colon ${ }^{(14-17)}$. For example, in the study by Furusawa et al. ${ }^{(15)}$, butyrylated starch was shown to be more effective than the high-amylose starch per se to regulate the differentiation of $\mathrm{T}$ cells in the colon and to suppress inflammatory and allergy responses which were connected with decreased colitis induced in mice. Application of butyric acid alone as a therapeutic agent is hindered due to difficulties in rapid metabolism, very short half-life and strong odour of butyrate, making direct oral consumption unacceptable. To overcome this drawback, there is a growing interest in developing SCFA derivatives with stable properties until transported to the targeted organs. The most well-known derivative is tributyrin (TB), a pro-drug of butyrate, which has been shown to reduce release of pro-inflammatory cytokines ${ }^{(18)}$, induce growth inhibition and apoptosis of colon cancer cells, even more effectively than butyrate $^{(19)}$. The effectiveness of TB has also been evaluated in rat models of colon ${ }^{(20)}$ and liver cancer ${ }^{(21,22)}$.

In the present study, two SCFA-based ester products, monobutyrin (MB) and TB, were mixed into high-fat control (HFC) diets and given to conventional rats for 3 weeks. A high-fat setting was used to provoke a low formation of butyrate and a more inflammatory environment in the colon, as previously reported ${ }^{(8)}$ in the same rat model. The aim was to investigate whether these esters would reach the colon and affect the colonic properties of some metabolic risk-markers associated with chronic inflammation of the gut. For this purpose, the caecal content of SCFA and microbiota composition were analysed in the rats. Furthermore, the lipid profile (total cholesterol, LDL-cholesterol, HDL-cholesterol and TAG) and SCFA in the liver and serum were examined as well as serum LBP. Succinic acid and the expression of bile acid-related primary genes in the liver (Cyp7a1, Cyp8b1 and NrOb2) were also determined.

\section{Materials and methods}

\section{Diets}

MB and TB were kindly provided by Perstorp AB. To induce a pre-inflammatory state in the colon concerning the microbiota composition and gut metabolites (SCFA and succinic acid), all test diets containing the butyrins were prepared in a high-fat setting. A high-fat diet without any butyrins was used as a control (HFC) and a low-fat (LF) diet was also included as a reference. All test diets were prepared according to the composition in Table 1. Casein was used as the protein source, whereas cellulose was chosen as the fibre source since it is resistant to fermentation in the gut (humans and rats) and therefore gives low amounts of SCFA ${ }^{(23)}$. Wheat starch was used to adjust the DM content. The type of wheat starch used in the present study has been previously shown to be completely digested and does not contribute to subsequent
Table 1. Composition ( $\mathrm{g} / \mathrm{kg}$ dry weight) of the test diets

\begin{tabular}{|c|c|c|c|c|c|}
\hline $\begin{array}{l}\text { Diet... } \\
\text { Components }\end{array}$ & LF & HFC & $0.1 \mathrm{MB}$ & $\mathrm{MB}$ & TB \\
\hline Casein* & $150 \cdot 0$ & $150 \cdot 0$ & $150 \cdot 0$ & $150 \cdot 0$ & $150 \cdot 0$ \\
\hline DL-Methionine* & 1.2 & $1 \cdot 2$ & $1 \cdot 2$ & $1 \cdot 2$ & $1 \cdot 2$ \\
\hline Butter† & 0.0 & $180 \cdot 0$ & $180 \cdot 0$ & $180 \cdot 0$ & 180.0 \\
\hline Rapeseed oil & $50 \cdot 0$ & $50 \cdot 0$ & $50 \cdot 0$ & $50 \cdot 0$ & $50 \cdot 0$ \\
\hline Sucrose & $100 \cdot 0$ & $100 \cdot 0$ & $100 \cdot 0$ & $100 \cdot 0$ & $100 \cdot 0$ \\
\hline Cellulose & $50 \cdot 0$ & $50 \cdot 0$ & $50 \cdot 0$ & $50 \cdot 0$ & 50.0 \\
\hline Mineral mixture§ & $48 \cdot 0$ & $48 \cdot 0$ & $48 \cdot 0$ & $48 \cdot 0$ & $48 \cdot 0$ \\
\hline Vitamin mixture\| & 8.0 & $8 \cdot 0$ & $8 \cdot 0$ & $8 \cdot 0$ & 8.0 \\
\hline Choline chloride* & 2.0 & $2 \cdot 0$ & 2.0 & $2 \cdot 0$ & $2 \cdot 0$ \\
\hline Ester product & 0.0 & 0.0 & 1.0 & $5 \cdot 0$ & 5.0 \\
\hline Wheat starch & $590 \cdot 8$ & $410 \cdot 8$ & $409 \cdot 8$ & $405 \cdot 8$ & $405 \cdot 8$ \\
\hline
\end{tabular}

LF, low-fat; HFC, high-fat control; $0.1 \mathrm{MB}$, monobutyrin (1 g/kg diet); MB, monobutyrin ( $5 \mathrm{~g} / \mathrm{kg}$ diet); TB, tributyrin (5 $\mathrm{g} / \mathrm{kg}$ diet).

* Sigma-Aldrich.

† Arla Foods.

† FMC BioPolymer.

§Containing $(\mathrm{g} / \mathrm{kg}): 0.37 \mathrm{CuSO}_{4} .5 \mathrm{H}_{2} \mathrm{O}, 1.4 \mathrm{ZnSO}_{4} .7 \mathrm{H}_{2} \mathrm{O}, 332.1 \mathrm{KH}_{2} \mathrm{PO}_{4}, 171.8$ $\mathrm{NaH}_{2} \mathrm{PO}_{4} .2 \mathrm{H}_{2} \mathrm{O}, 324.4 \mathrm{CaCO}_{3}, 0.068 \mathrm{KI}, 57.2 \mathrm{MgSO}_{4}, 7.7 \mathrm{FeSO}_{4} .7 \mathrm{H}_{2} \mathrm{O}, 3.4$ $\mathrm{MnSO}_{4} \cdot \mathrm{H}_{2} \mathrm{O}, 0.02 \mathrm{CoCl}_{6} \mathrm{H}_{2} \mathrm{O}, 101.7 \mathrm{NaCl}, 0.019$ chromium (III) chloride and 0.011 sodium selenite (Lantmännen).

\| Containing ( $\mathrm{g} / \mathrm{kg}$ ): 0.62 menadione, 2.5 thiamin hydrochloride, 2.5 riboflavin, 1.25 pyridoxine hydrochloride, 6.25 calcium pantothenate, 6.25 nicotinic acid, 0.25 folic acid, 12.5 inositol, $1.25 p$-aminobenzoic acid, 0.05 biotin, 0.00375 cyanocobalamin, 0.187 retinyl palmitate, 0.00613 calciferol, $25 \mathrm{D}$ - $\alpha$-tocopheryl acetate, 941.25 maize starch (Lantmännen).

ๆ Cargill; varied depending on the ester and fat content of the test diets.

formation of any SCFA in the caecum or in the bloodstream of rats ${ }^{(24)}$.

The study design resulted in five diets, including three test diets containing glycerol esters. The ester products were added in a concentration of $5 \mathrm{~g} / \mathrm{kg}$ in the diets calculated on a dry weight basis. These diets were abbreviated as MB or TB. In addition, a diet with $1 \mathrm{~g} / \mathrm{kg} \mathrm{MB}$ was included to get an idea about the dose-dependent effect of this product. This diet is abbreviated as $0.1 \mathrm{MB}$. The doses chosen were based on results from a pilot study and from previous work $^{(25)}$. The composition of $\mathrm{MB}$ and $\mathrm{TB}$ is shown in Supplementary Table S1.

\section{Animals and experimental design}

The present study was conducted based on guidelines for the protection of laboratory animals used for scientific purposes, and it was approved by the Local Ethical Review Committee for animal experiments in Lund, Sweden (approval number M 295-12).

Male rats, Rattus norvegicus, of Wistar strain (Taconic) with an initial average weight of 142 (SEM 8) g, were randomly divided into five groups of seven. Each group was housed into two cages containing three or four rats per cage. After $3 \mathrm{~d}$ acclimatisation to the environment $\left(21^{\circ} \mathrm{C}, 12 \mathrm{~h}\right.$ light-12 h dark cycle), they were given the test diets. The experiment was performed in three consecutive weeks in which the animals were allowed to have free access to the test diets and water placed on the cage lid. New feed was added every $2-3 \mathrm{~d}$, while residues were weighed and recorded. Rat body weights were recorded every week.

After the experimental period, the rats were anaesthetised for tissue harvesting by a subcutaneous injection mixture 
(1:1:2) of Hypnorm (Division of Janssen-Cilag Limited, Janssen Pharmaceutica), Dormicum (F. Hoffmann-La Roche AG) and autoclaved Milli-Q Millipore water, at a dose of $0 \cdot 15 \mathrm{ml} / 100 \mathrm{~g}$ body weight. Rats from two different groups were randomly chosen for dissection on the same day. The rats were fed with the actual diets until dissection. Blood samples were collected from the hepatic portal vein and placed immediately in serum tubes (SST ${ }^{\mathrm{TM}}$ II Advance, Plus Blood Collection Tubes, BD Vacutainer). The serum samples, obtained after centrifugations, were stored at $-40^{\circ} \mathrm{C}$ until analysis of SCFA, LBP, cholesterol and TAG. The caecum was removed and weighed with and without its content. Caecal tissue was washed with Milli-Q Millipore water, while content was subjected to $\mathrm{pH}$ measurement before being stored at $-20^{\circ} \mathrm{C}$ until analysis of SCFA and gut microbiota composition. Other organs including the liver, spleen, stomach, small intestine and colon were removed, weighed and stored at $-80^{\circ} \mathrm{C}$ for further analysis. SCFA and succinic acid were analysed in the liver. Blood glucose was measured immediately by a HemoCue ${ }^{\circledR}$ Glucose $201^{+}$Analyzer (HemoCue AB) after the collection of blood from the hepatic portal vein.

\section{Analyses}

Carboxylic acids. SCFA in caecal content were extracted with acidified water before being measured by a methodology using direct injection $\mathrm{GC}^{(26)}$. Concentrations of SCFA in serum samples were pre-enriched and extracted by hollow fibre before being injected and analysed with $\mathrm{GC}^{(27)}$.

SCFA together with succinic acid were also analysed in freeze-dried liver samples. For SCFA, the same method as for caecal content was applied ${ }^{(26)}$. Succinic acid was measured by ion-exclusion chromatography with a method developed at the department (MIC-2 Advanced modular IC; Metrohm AG). Approximately, $100 \mathrm{mg}$ of liver samples were diluted with Milli-Q Millipore water, centrifuged at $4000 \mathrm{rpm}$ for 20 min, filtered through a $0.45 \mathrm{~mm}$ syringe filter, and injected into a Metrosep organic column $(250 \times 7.8 \mathrm{~mm}$, Metrohm). The column oven temperature was $70^{\circ} \mathrm{C}$ and the effluent $\left(0.5 \mathrm{~mm}_{-} \mathrm{H}_{2} \mathrm{SO}_{4}\right)$ flow rate was $0.6 \mathrm{ml} / \mathrm{min}$. The suppressor was regenerated using a solution of $10 \mathrm{~mm}-\mathrm{LiCl}$, followed by Milli-Q Millipore water. The analysis time for each run lasted for $25 \mathrm{~min}$.

Cholesterol and TAG in blood and liver. Freeze-dried liver samples were used for the determination of total cholesterol, HDL- cholesterol, LDL-cholesterol and TAG. Lipids were extracted using a modified method with low-toxicity solvent ${ }^{(28)}$. Briefly, $20 \mathrm{mg}$ were dissolved in a 3:2 solution containing hexane (Sigma-Aldrich), isopropanol (Merck), with $0.005 \%$ (v/w) 2,6-di-tert-butyl-4-metylphenol (Merck) before being centrifuged, and the supernatants were evaporated under $\mathrm{N}_{2}$ flow at room temperature. The dried lipid extracts were re-dissolved in $1 \mathrm{ml}$ of isopropanol containing $1 \%$ (v/v) Triton X100 (Sigma-Aldrich). Total cholesterol and TAG in liver and serum were determined spectrophotometrically using Infinity Cholesterol/Triglyceride
Liquid Stable Reagent (Thermo Scientific), while liver HDL and LDL were measured using the reagents HDLCholesterol Plus and LDL-Cholesterol (Thermo Scientific).

Lipopolysaccharide-binding protein. Levels of LBP in serum were determined using an LBP ELISA kit for a wide variety of species and the protocol was supplied by the manufacturer (Hycult Biotech).

Caecal microbiota. Extraction of DNA was performed from 50-100 mg of rat caecal content using the QIAamp Fast DNA Stool Mini Kit (Qiagen), according to the manufacturer's protocol using an additional bead-beating step. Measurement of DNA concentration was performed using a Qubit 2.0 Fluorometer (Life Technologies). See Supplementary material for further details.

Gene expression. PrimePCR for Nr0b1, Cyp7a1 and Cyp8b1 was purchased from Bio-Rad. See Supplementary material for further details.

\section{Statistical evaluation}

Minitab statistical software (version 17.2.1; AutoBVT Microsoft) was used to evaluate significant differences between groups. Each sample from all analyses was performed in duplicate, except in the gene expression experiment where every sample was tested in triplicate. Grubbs' test was used to check normality of the data. If the data were not normally distributed, differences between groups were identified after Box-Cox transformation or using the non-parametric Kruskall-Wallis test. One-way ANOVA was applied to determine differences in means between groups. After ANOVA, Dunnett's method was applied to specifically identify which groups, including the group fed the LF diet, were significantly different from the HFC group, to evaluate whether the butyrins could counteract the adverse effects induced by high fat feeding. Furthermore, high-fat butyrin diets were also compared with the LF diet, to confirm the effects of the butyrins. For microbiota analysis, the same statistical approach (from GraphPad Prism 7) was used to find differences in relative abundances, at phylum and genus levels, and to correct for multiple comparisons. Pearson's correlation was used to evaluate association between parametric variables, while Spearman's correlation was applied for non-parametric data. Partial least-squares-projection-to-latent-structures-discriminant analysis (PLS-DA) from SIMCA software (version 14; Umetrics) was used to analyse and visualise how the gut microbiota data at genus level varied in relation to the liver lipids. The confidence level in all statistical tests was specified at $95 \%$. $P$ values $<0.05$ were statistically significant, while $0 \cdot 1 \geq P$ values $\geq 0 \cdot 05$ were considered as tendency. Results are presented as means with their standard errors. 


\section{Results}

\section{Body weight gain, tissue weights and $\mathrm{pH}$}

All rats appeared healthy and active, and gained weight gradually throughout the experiment (Table 2). At the end of the experiment, rats given the $\mathrm{MB}$ diet had a $7 \%$ lower final body weight compared with those fed the HFC diet $(P=$ 0.024). Body weight gain was similar between all groups fed high-fat diets. The LF diet group had a higher body weight gain than the rats fed the HF diets, but by taking the feed intake into account (feed efficiency ratio) the body weight gain was similar for all groups $(0 \cdot 29-0 \cdot 33)$. Caecal $\mathrm{pH}$ was between $7 \cdot 4$ and $7 \cdot 7$.

No difference was found in absolute weights of the liver, spleen and caecal tissue.

\section{Carboxylic acids}

Caecum. Addition of TB to the HFC diet reduced total caecal amounts of SCFA from 82 to $56 \mu \mathrm{mol}$ (Table 3; $P=$ 0.027). The amount of individual SCFA was also lower and these values were significant for all acids except butyric acid and isobutyric acid (acetic acid $(P=0.051)$, propionic acid $(P<0.0001)$, valeric acid $(P=0.024)$ and isovaleric acid $(P$ $=0.027))$. Rats in the $\mathrm{MB}$ group showed a significant decrease in propionic acid and isovaleric acid $(P=0.02$ and $P=0.03$, respectively) compared with the HFC group. Furthermore, both MB and TB groups had a significantly higher ratio of acetic acid:propionic acid compared with the HFC group $(P=0.02$ and $P=0.008$, respectively) (Supplementary Fig. S1). No difference in the ratios of acetic acid:butyric acid or acetic acid:propionic plus butyric acid between the test groups and the HFC group could be seen. The proportion of propionic acid was significantly lower in the MB and TB groups (11\%) compared with the HFC group (13\%; $P<0.0001 ;$ Supplementary Table S2). The SCFA profile of the $0.1 \mathrm{MB}$ group did not differ from that of the HFC group.

The total and specific SCFA were generally lower with groups fed high-fat diets compared with the group fed the
$\mathrm{LF}$ diet, and reach significance for the $\mathrm{MB}$ and TB groups in most cases $(P<0.0001$ to $P<0 \cdot 05)$. An exception was butyric acid that was similar in all groups.

Serum. Rats fed the MB and TB diets generally exhibited lower serum concentrations of SCFA compared with those consuming the HFC diet and reached significance for propionic acid (Table 3; $P=0.003$ ) and isobutyric acid $(P=$ 0.01). Interestingly, butyric acid concentrations were somewhat higher with the $\mathrm{MB}$ and $\mathrm{TB}$ diets (58 and 47 $\mu \mathrm{mol} / \mathrm{l})$ compared with the HFC diet $(38 \mu \mathrm{mol} / \mathrm{l})$, but the differences were not significant.

There was no difference in serum SCFA between rats fed the LF and HFC diets.

Liver. There was no difference in the amount of SCFA in the liver of rats after supplementation of butyrins compared with those fed the HFC diet. However, the TB group tended to have higher concentrations of total SCFA $(P=0 \cdot 093)$, acetic acid $(P=0.074)$ and propionic acid $(P=0.092)$ compared with the MB group (Table 3). Furthermore, the higher dose of $\mathrm{MB}$ exhibited markedly higher amounts of isovaleric acid than the $0.1 \mathrm{MB}$ group $(P=0.024)$. No difference in the amount of valeric acid was found between any of the groups. The LF group had higher total liver SCFA, acetic acid and butyric acid than the HFC group $(P<0 \cdot 05)$.

Regarding succinic acid, there were no differences in the concentration between the high-fat diets (Fig. 1(b)). However, when calculating the amount of succinic acid in relation to body weight it was significantly lower in MB and TB groups than in the HFC group (Fig. 1(a); $P=0.033, P=$ $0 \cdot 023$, respectively). Furthermore, the concentration of succinic acid was lower in the group fed the LF diet compared with the group fed the HFC diet (Fig. 1(b); $P=0.045$ ), and very similar to the MB and TB groups. The ratio between succinic acid and butyric acid was higher in the group fed the HFC diet than the group fed the LF diet (14.1 v. $8.4 \mu \mathrm{mol} /$

Table 2. Final body weight, body weight gain, total feed intake, feed efficiency ratio (body weight gain/feed intake), wet and freeze-dried liver weight, spleen weight, caecal tissue, caecal content and caecal pH in rats fed a low-fat (LF) diet, a high-fat control (HFC) diet or the HFC diet supplemented with monobutyrin at $1 \mathrm{~g} / \mathrm{kg}$ diet $(0.1 \mathrm{MB}), \mathrm{MB}$ at $5 \mathrm{~g} / \mathrm{kg} \operatorname{diet}(\mathrm{MB})$ or tributyrin at $5 \mathrm{~g} / \mathrm{kg} \operatorname{diet}(\mathrm{TB})$ for $21 \mathrm{~d}$ (Mean values with their standard errors; $n$ 7)

\begin{tabular}{|c|c|c|c|c|c|c|c|c|c|c|}
\hline \multirow{2}{*}{$\begin{array}{l}\text { Group... } \\
\text { Parameters }\end{array}$} & \multicolumn{2}{|c|}{ LF } & \multicolumn{2}{|c|}{$\mathrm{HFC}$} & \multicolumn{2}{|c|}{$0.1 \mathrm{MB}$} & \multicolumn{2}{|c|}{ MB } & \multicolumn{2}{|c|}{ TB } \\
\hline & Mean & SEM & Mean & SEM & Mean & SEM & Mean & SEM & Mean & SEM \\
\hline Final body weight (g) & 292 & 8 & 270 & 4 & 275 & 7 & $252^{*}+\dagger \dagger$ & 7 & $256+\dagger$ & 4 \\
\hline Body weight gain $(\mathrm{g})$ & 137 & 6 & 120 & 4 & 129 & 7 & $113+$ & 6 & $116 \dagger$ & 4 \\
\hline Total feed intake (g/rat) & 453 & 2 & 417 & 2 & 389 & 10 & 347 & 9 & 355 & 2 \\
\hline Feed efficiency ratio ( $\mathrm{g} / \mathrm{g}$ feed) & 0.30 & 0.01 & 0.29 & 0.01 & 0.33 & 0.02 & 0.33 & 0.02 & 0.33 & 0.01 \\
\hline Wet liver weight $(\mathrm{g})$ & 11 & 0.4 & 10 & 0.4 & 10 & 0.3 & $9 \dagger$ & 0.3 & $10 \dagger$ & 0.2 \\
\hline Freeze-dried liver weight $(\mathrm{g})$ & 3.3 & 0.2 & 3.1 & 0.1 & 3.1 & 0.1 & $2 \cdot 8 \dagger$ & 0.1 & 2.9 & 0.1 \\
\hline Spleen weight $(\mathrm{g})$ & 0.6 & 0.03 & 0.6 & 0.03 & 0.6 & 0.02 & 0.5 & 0.03 & 0.6 & 0.03 \\
\hline Caecal tissue weight (g) & 0.5 & 0.02 & 0.5 & 0.02 & 0.5 & 0.03 & 0.6 & 0.08 & 0.5 & 0.02 \\
\hline Caecal content weight $(\mathrm{g})$ & 1.7 & 0.2 & $2 \cdot 2$ & 0.3 & $2 \cdot 1$ & 0.3 & 1.9 & 0.2 & $1 \cdot 7$ & 0.2 \\
\hline Caecal pH & 7.4 & 0.1 & 7.5 & 0.1 & 7.5 & 0.1 & $7 \cdot 7$ & 0.3 & $7 \cdot 6$ & 0.3 \\
\hline
\end{tabular}

* Mean value was significantly different from that of the HFC group $(P<0.05$; one-way ANOVA and Dunnett's test).

Mean value was significantly different from that of the LF group: $\dagger P<0.05$, $\dagger \dagger P<0.01$, $\dagger+\uparrow P<0.001$ (one-way ANOVA and Dunnett's test) 
Table 3. SCFA in the caecum, portal serum, and liver of rats fed a low-fat (LF) diet, a high-fat control (HFC) diet or the HFC diet supplemented with monobutyrin at $1 \mathrm{~g} / \mathrm{kg}$ diet $(0.1 \mathrm{MB}), \mathrm{MB}$ at $5 \mathrm{~g} / \mathrm{kg}$ diet (MB) or tributyrin at $5 \mathrm{~g} / \mathrm{kg} \operatorname{diet}(\mathrm{TB})$ for $21 \mathrm{~d}$

(Mean values with their standard errors; $n 7$ )

\begin{tabular}{|c|c|c|c|c|c|c|c|c|c|c|}
\hline \multirow{2}{*}{$\begin{array}{l}\text { Group... } \\
\text { Locations }\end{array}$} & \multicolumn{2}{|c|}{ LF } & \multicolumn{2}{|c|}{ HFC } & \multicolumn{2}{|c|}{$0.1 \mathrm{MB}$} & \multicolumn{2}{|c|}{ MB } & \multicolumn{2}{|c|}{ TB } \\
\hline & Mean & SEM & Mean & SEM & Mean & SEM & Mean & SEM & Mean & SEM \\
\hline \multicolumn{11}{|c|}{ Caecal pool ( $\mu \mathrm{mol})$} \\
\hline Total & 100 & 11 & 82 & 10 & 85 & 5 & $65 \dagger$ & 6 & $56^{*} \dagger \dagger$ & 7 \\
\hline Acetic & 71 & 8 & 57 & 7 & 60 & 4 & $48 \dagger$ & 5 & $41 \dagger \dagger$ & 5 \\
\hline Propionic & 16 & 2 & $11 \dagger$ & 1 & 12 & 1 & $8^{*}+† \dagger \dagger$ & 1 & $6^{\star \star \star}+† \dagger †$ & 1 \\
\hline Butyric & 9 & 2 & 9 & 1 & 8 & 1 & 8 & 1 & 6 & 1 \\
\hline Valeric & 1.6 & 0.2 & 1.5 & 0.2 & 1.6 & 0.1 & 1.2 & 0.1 & $1.0^{*} \dagger$ & 0.1 \\
\hline Isobutyric & 1.6 & 0.2 & $1 \cdot 2$ & 0.3 & $1 \cdot 2$ & 0.1 & $0.7 \dagger \dagger$ & 0.1 & $0.8 \dagger$ & 0.2 \\
\hline Isovaleric & 1.32 & 0.2 & 1.35 & 0.2 & 1.22 & 0.1 & $0.81^{*}$ & 0.1 & 0.88 & 0.1 \\
\hline \multicolumn{11}{|c|}{ Portal serum concentration $(\mu \mathrm{mol} / \mathrm{l})$} \\
\hline Total & 743 & 32 & 753 & 80 & 822 & 63 & 693 & 46 & 632 & 46 \\
\hline Acetic & 628 & 35 & 635 & 64 & 712 & 54 & 575 & 30 & 540 & 41 \\
\hline Propionic & 47 & 2 & 45 & 6 & 42 & 4 & $28^{*}+\dagger$ & 4 & $21^{* \star}+\dagger \dagger$ & 1 \\
\hline Butyric & 32 & 2 & 38 & 6 & 36 & 6 & 58 & 13 & 47 & 5 \\
\hline Valeric & 9 & 2 & 13 & 2 & 13 & 2 & 17 & 2 & 14 & 2 \\
\hline Isobutyric & 14 & 1 & 13 & 1 & 11 & 1 & $8^{*} \dagger$ & 1 & $8^{*} \dagger$ & 1 \\
\hline Isovaleric & 15 & 3 & 11 & 2 & 8 & 2 & 8 & 1 & 7 & 1 \\
\hline \multicolumn{11}{|l|}{ Liver $(\mu \mathrm{mol})$} \\
\hline Total & $304^{\star \star \star *}$ & 33 & 147†††† & 25 & 144†††† & 12 & 127†††† & 8 & $186+\dagger$ & 16 \\
\hline Acetic & $288^{* * * *}$ & 31 & 136†††† & 24 & 136†††† & 11 & 113†††† & 8 & 171††† & 15 \\
\hline Propionic & $4 \cdot 7$ & 0.4 & $3 \cdot 7$ & 0.5 & $3 \cdot 2 \dagger$ & 0.4 & $3.1 \dagger$ & 0.2 & $4 \cdot 3$ & 0.2 \\
\hline Butyric & $2 \cdot 8^{*}$ & 0.3 & $2 \cdot 1 \dagger$ & 0.1 & $1.6+\dagger \dagger$ & 0.3 & $2.0 \dagger$ & 0.1 & $2 \cdot 1$ & 0.1 \\
\hline Valeric & $1 \cdot 1$ & 0.2 & 0.5 & 0.1 & 0.5 & 0.1 & 0.6 & 0.1 & 0.6 & 0.1 \\
\hline Isovaleric & $9 \cdot 1$ & $3 \cdot 1$ & 4.9 & 1.5 & $3 \cdot 3$ & 0.8 & 8.0 & $1 \cdot 0$ & $7 \cdot 1$ & 1.0 \\
\hline
\end{tabular}

Mean value was significantly different from that of the HFC group: ${ }^{*} P<0.05,{ }^{* *} P<0.01,{ }^{* * *} P<0.001,{ }^{* * * *} P<0.0001$ (one-way ANOVA and Dunnett's test).

Mean value was significantly different from that of the LF group: $+P<0.05$, †† $P<0.01$, †† $P<0.001$, †††† $P<0.0001$ (one-way ANOVA and Dunnett's test).

$\mu \mathrm{mol} ; P<0 \cdot 05)$. It decreased when $\mathrm{MB}$ and TB was added to the diet, but not significantly.

Correlations. In previous studies, caecal amounts of propionic and butyric acids formed in rats from different fibre-rich food components have been reflected and related to those in portal blood ${ }^{(29)}$. There was a strong correlation (Fig. 2; $r 0.664 ; P<0.001)$ of caecal propionic acid to those in portal serum also in this study, but not with butyric acid. Furthermore, no correlation was seen between any of the SCFA in the liver and those in the caecum or portal blood, except a tendency for valeric acid to those in portal serum $(r$ $0 \cdot 412 ; P=0 \cdot 071)$.

\section{Cholesterol and TAG}

Liver. Incorporation of $\mathrm{MB}$ and $\mathrm{TB}$ to a $\mathrm{HFC}$ diet resulted in an improvement of the liver lipid profile, as evaluated by a significant decrease in hepatic total cholesterol concentrations (Fig. 1(c); $P<0.0001$ for $\mathrm{MB}$ and $P=0.0022$ for TB, respectively), LDL-cholesterol (Fig. 1(d); $P<0 \cdot 0001$, $P=0 \cdot 0005$, respectively) and LDL:HDL ratio (Fig. $1(\mathrm{f}) ; P=$ $0.0006, \quad P=0.0002$, respectively). The effects on total cholesterol and LDL concentrations were more pronounced in the MB group than in the TB group, as evidenced with 51 and $12 \%$ reductions in total and LDL-cholesterol, respectively, by $\mathrm{MB}$ treatment and 24 and $10 \%$ reductions, respectively, by TB treatment. Interestingly, HDL-cholesterol concentrations tended to be higher in the TB group than the HFC group (Fig. 1(e); $P=0 \cdot 0748$ ), which could not be seen with MB. The lipid profile induced by high-fat feeding was not affected by $0.1 \mathrm{MB}$. TAG concentrations remained similar among all groups (Fig. $1(\mathrm{~g})$ ).

The group fed the LF diet had lower total cholesterol concentrations than the group fed the HFC diet (Fig. 1(c); $P=$ 0.007). Furthermore, it was similar to the group fed TB but higher than the group fed MB $(P=0.0025)$.

In addition, the total cholesterol and LDL concentrations in the liver were positively correlated with the amount of succinic acid $(r 0.497, P=0.003$ and $r 0.43, P=0 \cdot 01$, respectively).

Serum. None of the added esters caused any changes in serum concentrations of total cholesterol and TAG (Fig. 3(a) and (b)).

\section{Lipopolysaccharide-binding protein}

Concentrations of the inflammatory marker LBP were similar between the test groups and the HFC group (Fig. 3(c)). No significant differences between groups fed the HFC and LF diets could be seen either, although LBP was lower with the LF group.

\section{Gene expression in the liver}

No significant change was observed in the expression of Cyp7a1 $(P=0.12)$ and NrOb2 in the liver between the groups (Table 4). In contrast, relative mRNA expression of Cyp8b1 in the MB group was lower than in the HFC group $(P=0.031)$, suggesting that a lower amount of bile acids had been formed 
(a)

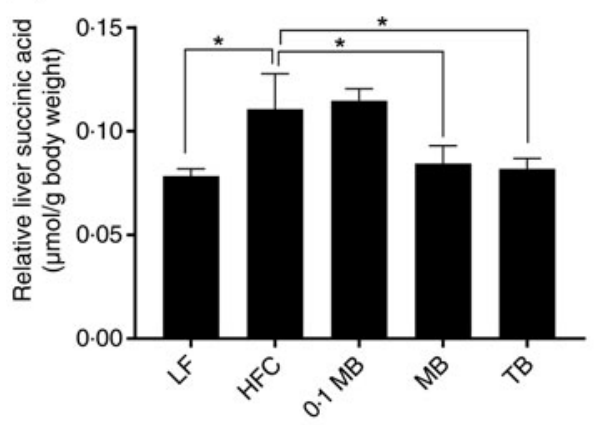

(c)

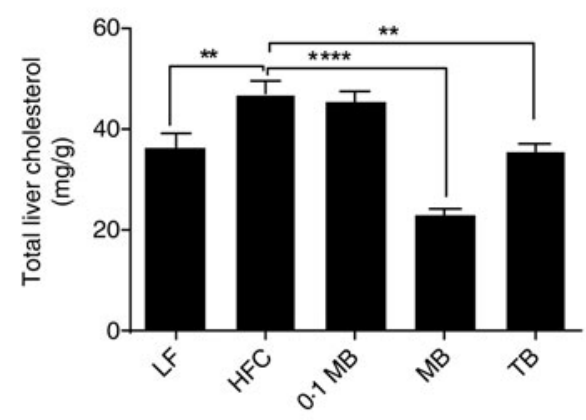

(e)
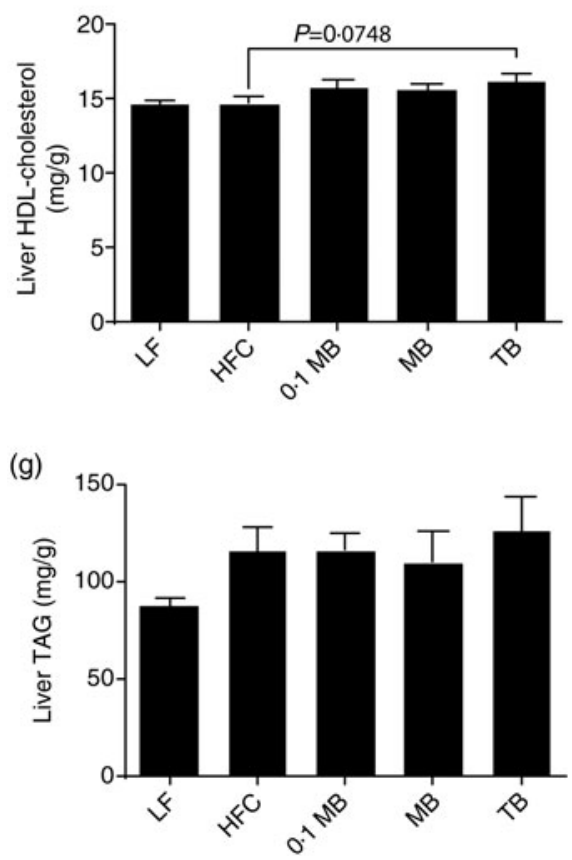

(b)

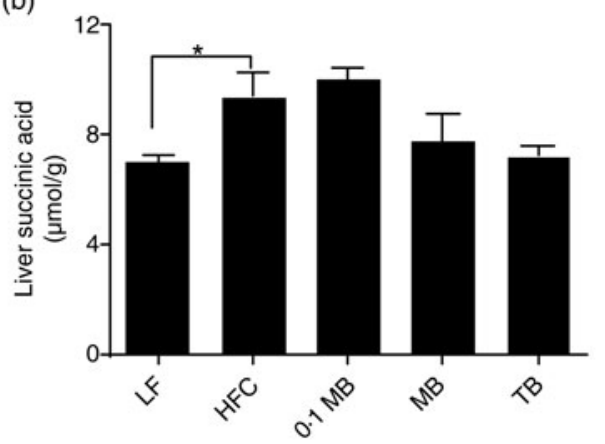

(d)

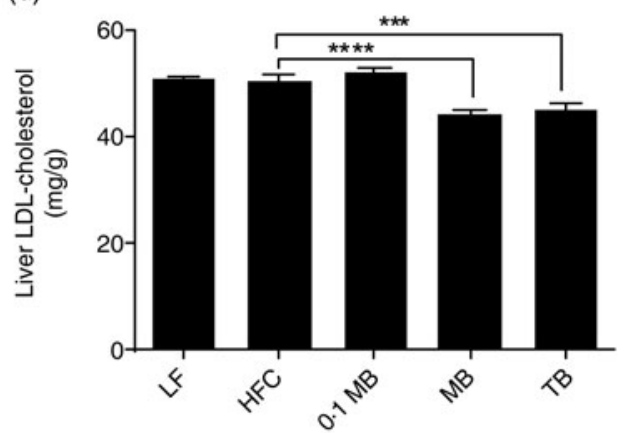

(f)

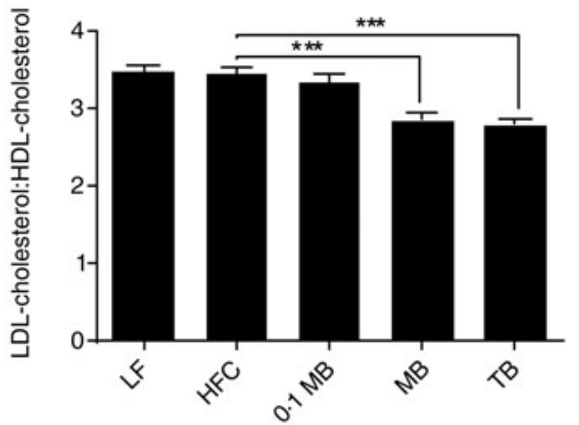

Fig. 1. Liver succinic acid and lipid concentrations of rats fed a low-fat (LF) diet, a high-fat control (HFC) diet or the HFC diet supplemented with monobutyrin at $1 \mathrm{~g} / \mathrm{kg}$ diet (0.1 MB), MB at $5 \mathrm{~g} / \mathrm{kg}$ diet (MB) or tributyrin at $5 \mathrm{~g} / \mathrm{kg}$ diet (TB) for $21 \mathrm{~d}$ ( $n$ 7/group). (a) Relative succinic acid (total amount of succinic acid in the liver/final body weight, $\mu \mathrm{mol} / \mathrm{g}$ ); (b) succinic acid concentration ( $\mu \mathrm{mol} / \mathrm{g}$ ); (c) total cholesterol (mg/g); (d) LDL-cholesterol (mg/g); (e) HDL-cholesterol (mg/g); (f) LDL-cholesterol: HDL-cholesterol ratio; $(\mathrm{g})$ TAG (mg/g). Values are means, with standard errors represented by vertical bars. Mean value was significantly different from that of the HFC group: ${ }^{*} P<0.05,{ }^{\star *} P<0.01,{ }^{* \star *} P<0.001,{ }^{* \star * *} P<0.0001$ (one-way ANOVA and Dunnett's test).

due to lower available amounts of cholesterol. Moreover, liver cholesterol was positively correlated with the expression of Cyp861 ( $r 0.546 ; P=0.004)$, and also Cyp7a1, although to a lesser extent $(r 0.441 ; P=0 \cdot 024)$.

There was no difference in gene expression between groups fed the LF diet and HFC diet.

\section{Caecal microbiota}

The gut microbiota from all high-fat groups were represented by seven phyla: Firmicutes, Bacteroidetes, Verrucomicrobia, Proteobacteria, Deferribacteres, Candidatus Saccharibacteria (known as TM7) and Tenecurites. No change in relative 


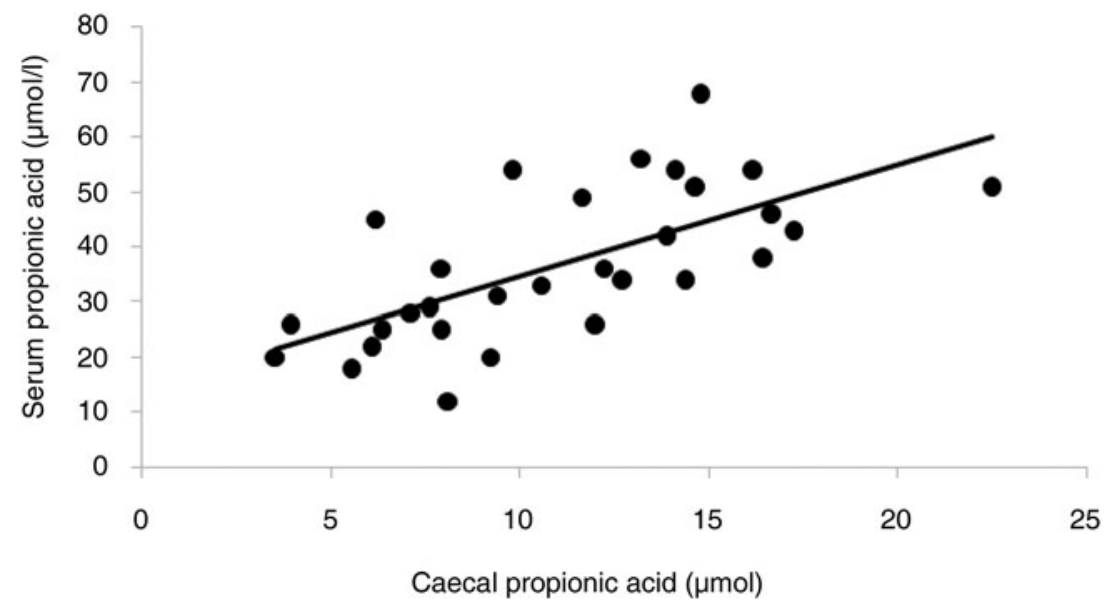

Fig. 2. Pearson's correlation of propionic acid in the caecum and portal serum of rats fed a low-fat diet, a high-fat control (HFC) diet or the HFC diet supplemented with monobutyrin at $1 \mathrm{~g} / \mathrm{kg}$ diet, monobutyrin at $5 \mathrm{~g} / \mathrm{kg}$ diet or tributyrin at $5 \mathrm{~g} / \mathrm{kg}$ diet for $21 \mathrm{~d}(r 0.664 ; P<0.001)$.

(a)

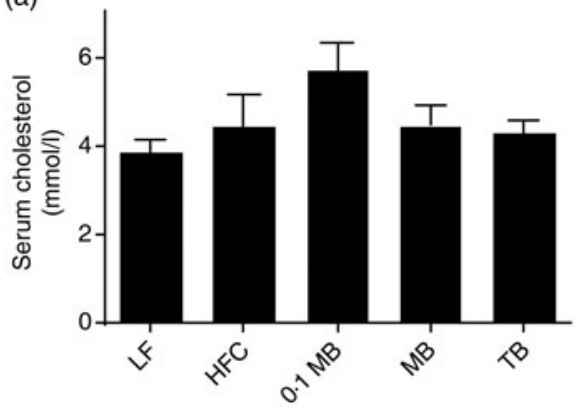

(c)

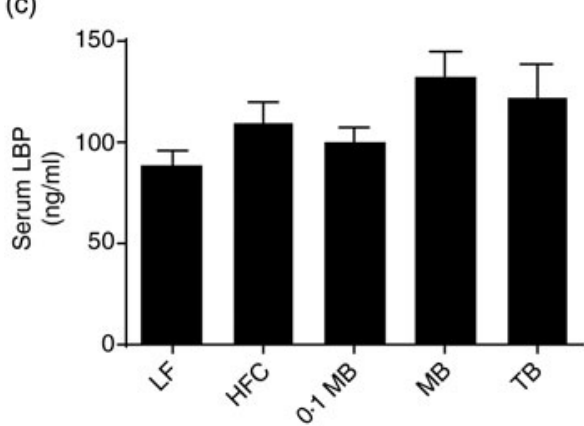

(b)

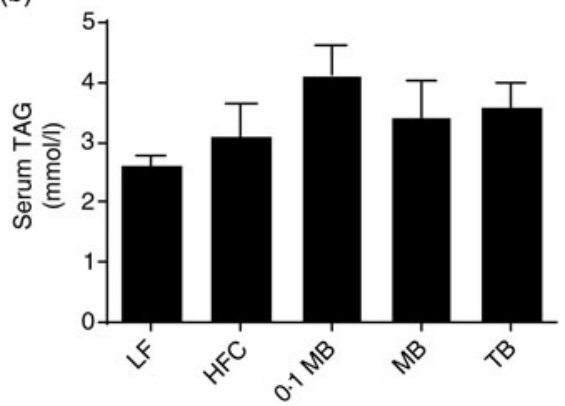

Fig. 3. Serum lipid and lipopolysaccharide-binding protein (LBP) concentrations of rats fed a low-fat (LF) diet, a high-fat control (HFC) diet or the HFC diet supplemented with monobutyrin at $1 \mathrm{~g} / \mathrm{kg}$ diet (0.1 MB), MB at $5 \mathrm{~g} / \mathrm{kg}$ diet (MB) or tributyrin at $5 \mathrm{~g} / \mathrm{kg} \operatorname{diet}(\mathrm{TB})$ for $21 \mathrm{~d}(n$ 7/group). (a) Total cholesterol (mmol/l); (b) TAG $(\mathrm{mmol} / \mathrm{l})$; (c) LBP $(\mathrm{ng} / \mathrm{ml})$. Values are means, with standard errors represented by vertical bars.

Table 4. Relative mRNA expression of Nrob2, Cyp7a1 and Cyp8b1 in the liver of rats fed a low-fat (LF) diet, a high-fat control (HFC) diet or the HFC diet supplemented with monobutyrin at $1 \mathrm{~g} / \mathrm{kg}$ diet (0.1 MB), MB at $5 \mathrm{~g} / \mathrm{kg}$ diet (MB) or tributyrin at $5 \mathrm{~g} / \mathrm{kg}$ diet (TB) for $21 \mathrm{~d}$ (Mean values with their standard errors; $n 7$, except $n 6$ for HFC)

\begin{tabular}{|c|c|c|c|c|c|c|c|c|c|c|}
\hline \multirow{2}{*}{$\begin{array}{l}\text { Group... } \\
\text { Genes }\end{array}$} & \multicolumn{2}{|c|}{ LF } & \multicolumn{2}{|c|}{ HFC } & \multicolumn{2}{|c|}{$0.1 \mathrm{MB}$} & \multicolumn{2}{|c|}{ MB } & \multicolumn{2}{|c|}{ TB } \\
\hline & Mean & SEM & Mean & SEM & Mean & SEM & Mean & SEM & Mean & SEM \\
\hline Nrob2 & 2.90 & 0.04 & $2 \cdot 83$ & 0.04 & 2.85 & 0.02 & $2 \cdot 76$ & 0.06 & 2.76 & 0.05 \\
\hline Сур7a1 & 3.09 & 0.07 & 2.92 & 0.07 & $2 \cdot 84$ & 0.08 & $2.66 \dagger \dagger$ & 0.09 & $2 \cdot 68 \dagger \dagger$ & 0.07 \\
\hline Сур8b1 & 2.54 & 0.04 & 2.52 & 0.04 & 2.51 & 0.02 & $2 \cdot 37^{*} \dagger$ & 0.06 & 2.42 & 0.03 \\
\hline
\end{tabular}

* Mean value was significantly different from that of the HFC group $(P<0.05$; one-way ANOVA and Dunnett's test).

Mean value was significantly different from that of the LF group: $\dagger P<0.05, \dagger \dagger P<0.01$ (one-way ANOVA and Dunnett's test). 
abundance was seen at phylum level, except for the TM7 phylum that was detected in the HFC diet, but not in any of the groups fed the butyrin diets $(P=0.0009$; Fig. 4(a)). This difference was concurrently reflected, at genus level, by the absence of an unclassified genus in the family F16 in all the butyrin groups (Fig. 4(b); $P=0 \cdot 0009$ ). Alterations were also observed at genus level within the three phyla Bacteroidetes, Firmicutes and Deferribacteres after supplementation of $\mathrm{MB}$ and $\mathrm{TB}$. Originating from the phylum Bacteroidetes, an unclassified genus in the family S24-7 showed a markedly decreased abundance in all test groups (Fig. 4(d); $P<0.0001$ ), while the abundance of Bacteroides tended to be higher in the $0.1 \mathrm{MB}$ group (Fig. 4(c); $P=0.06$ ) compared with the HFC group. Within the phylum Deferribacteres, an increased abundance of Mucispirillum was noted in the MB group (Fig. 4(e); $P=$ 0.038 compared with the HFC group and $P=0.018$ compared with the LF group). Interestingly, the abundance of two genera in the phylum Firmicutes, namely Dorea and $r c 4-4$, was significantly lower in $\mathrm{MB}$ and $\mathrm{TB}$ groups than in the HFC group (Fig. 4(f), $P=0.01$; Fig. 4(g), $P=0.001$ ).

The abundance of TM7, the unclassified genus in the family F16, Bacteroides, the unclassified genus in the family S24-7, Mucispirillum and $r c 4$ was similar in the HFC and LF groups, while Dorea was lower in the LF group than in the HFC group $(P<0 \cdot 05)$.

\section{Multivariate data analysis}

A multivariate data analysis was conducted to elucidate how different groups were related to each other concerning the abundance of the microbiota and cholesterol levels (Fig. 5 (a)). Treatments with different doses of MB (1 and $5 \mathrm{~g} / \mathrm{kg}$ ) resulted in a clear separation of these groups. Further, animals in the two groups, MB and TB, were clearly separated from the HFC group, as well as from the LF group, whereas the $0.1 \mathrm{MB}$ group was scattered on the same side as the HFC group. Fig. 5(b) represents the gut microbiota composition at the genus level and how these were related to some variables of liver lipids. The HFC group had higher values of liver cholesterol, LDL, LDL:HDL ratio and succinic acid, and was positively related to the abundance of Dorea and $r .4$. The analytical values with the $\mathrm{MB}$ and $\mathrm{TB}$ groups were, on the other hand, lower and correlated negatively with these bacterial genera.

\section{Discussion}

This study was performed to test if $\mathrm{MB}$ and $\mathrm{TB}$, added to a high-fat diet, could suppress any adverse high fat-induced outcomes, as evaluated by changes in carboxylic acid (SCFA and succinic acid) concentrations, microbiota composition, lipid profile and an inflammatory marker, LBP. The results showed that supplementation of $\mathrm{MB}$ and $\mathrm{TB}$, both at $5 \mathrm{~g} / \mathrm{kg}$, was effective in decreasing hepatic cholesterol concentrations, while a lower dose of $\mathrm{MB}(1 \mathrm{~g} / \mathrm{kg})$ had no effect. The cholesterol-lowering effect was accompanied by decreased expression of key enzymes involved in bile acid synthesis, and alterations in the microbiota composition with reduced abundance or almost absence of high fat-related inhabitants, but with minor changes in SCFA profile. MB seemed to have more effects than TB which might be due to that more $\mathrm{MB}$ on a molar basis was added to the diets.

\section{Monobutyrin and tributyrin alter the gut microbiota profile}

Supplementation of MB and TB to a HFC diet altered the caecal microbiota composition and completely abolished some microbial taxa. The effect was surprisingly obvious at the phylum level, with TM7 present only in the HFC group but totally absent in the MB- and TB-supplemented groups. In terms of counteracting inflammation, this finding is of great interest because higher abundance and diversity of TM7 have been found in inflammatory bowel disease (IBD) patients than in non-IDB subjects ${ }^{(30)}$. Moreover, TM7 is also involved in oral inflammation where this phylum has been suggested as a modifier shifting the microenvironment, especially in the subgingival plaque, towards a more inflammatory microbiota $^{(31)}$. Altogether, it could be indicated that both MB and TB had the ability to suppress growth or desirable living conditions of certain bacteria accompanied by high-fat feeding. However, it should be emphasised that the group fed the LF diet had a very high abundance of TM7 compared with the group fed the HFC diet. This may be due to its low content of substrate for the microbiota, microcrystalline cellulose and fat (bile acids), creating a starving environment for the microbiota. A positive control, containing a fermentable fibre component, would perhaps have given more insight into the anti-microbial effects of $\mathrm{MB}$ and $\mathrm{TB}$.

\section{Associations between liver cholesterol and inflammatory markers and microbial taxa induced by monobutyrin and tributyrin}

Besides the microbial shift at the phylum level, changes at genus level further revealed a potential link between microbiota and the cholesterol-lowering effect observed in the liver. For instance, the relative abundance of Dorea and $\mathrm{rC}_{4}-4$, which are generally higher in rodents with diet-induced obesity ${ }^{(32)}$, was reduced by both the MB and TB supplementations. Furthermore, the abundance of Dorea was reduced to similar levels as in the group fed the LF diet, indicating inhibitory effect of esters on this genus. In fact, a positive association has been reported between Dorea with serum total cholesterol and LDL in high fat-induced hyperlipidaemic rats ${ }^{(33)}$, while a decreased abundance of Dorea after consumption of $\beta$-glucan (yields butyric acid) improves CVD risk factors, lowering TAG levels in mildly hypercholesterolaemic individuals ${ }^{(34)}$. In contrast to Dorea, the genus Mucispirillum increased in the MB group compared with the HFC group. Mucispirillum is identified as an inhabitant colonising the mucus layer of the gastrointestinal tract of rodents, and may be important to prevent disease development ${ }^{(35)}$. For instance, under impaired colonic conditions such as colitis in mice, a rapid decrease of this genus during early infection was observed and prolonged until full regeneration of the mucus layer was established ${ }^{(36)}$. Furthermore, in high-grain-fed goats (a model 
(a)

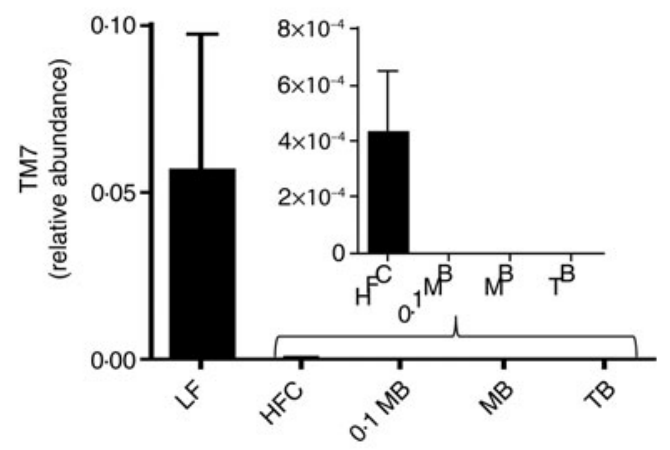

(c)

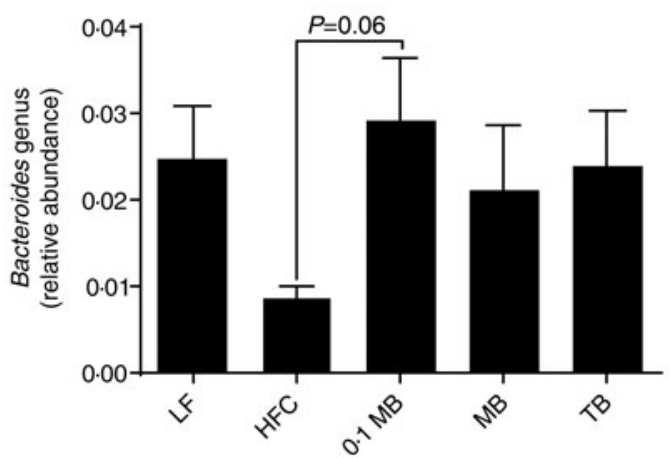

(e)

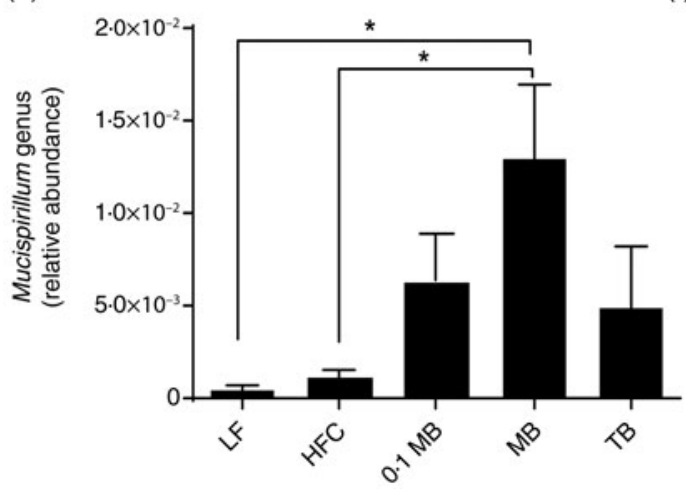

(b)

(d)

(f)
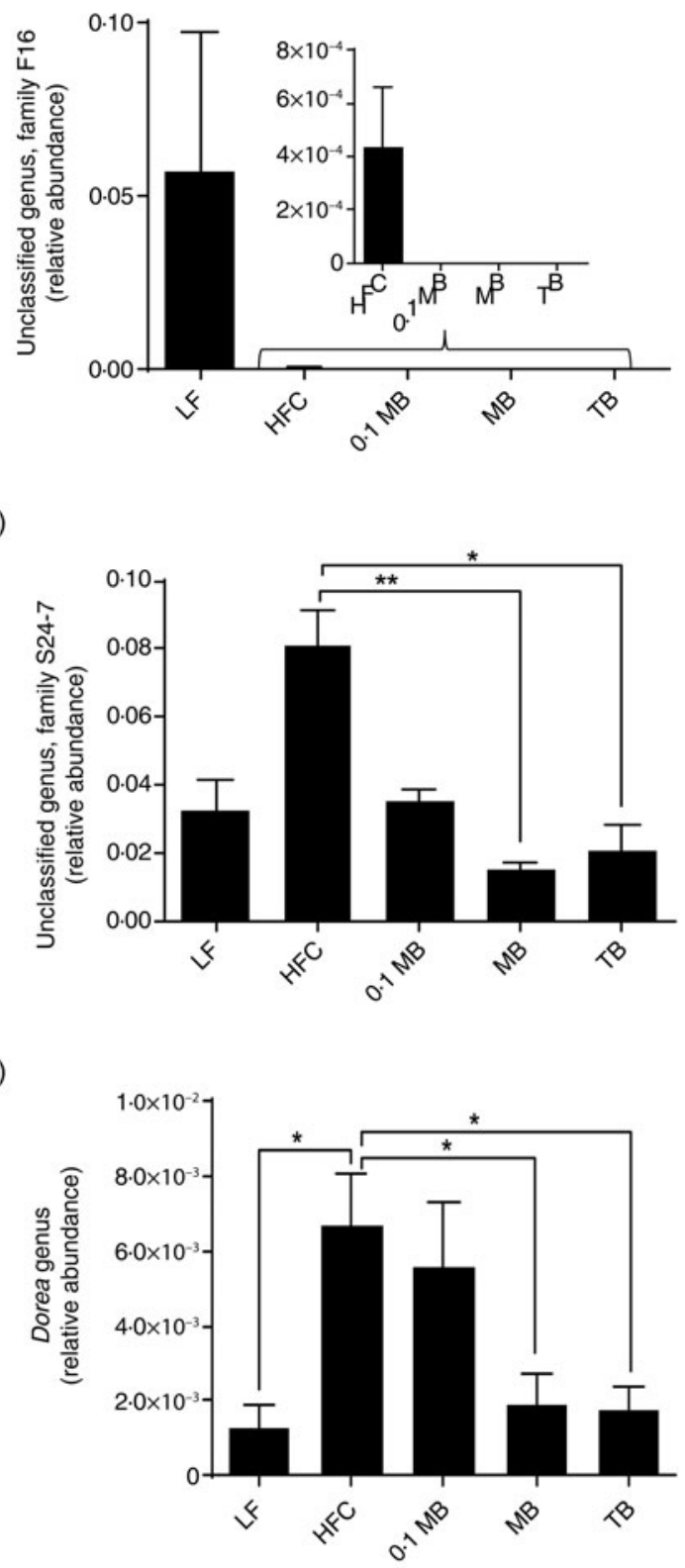

(g)

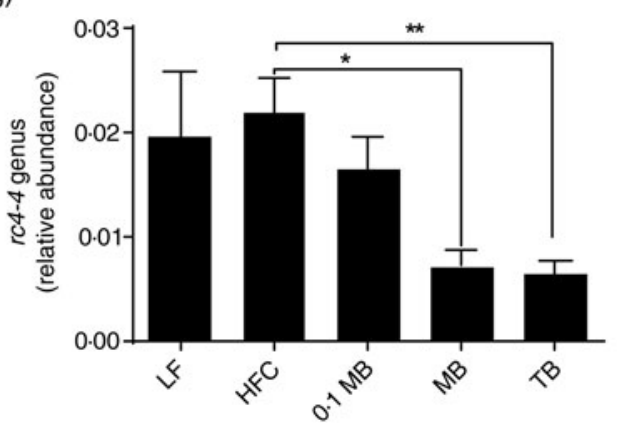

Fig. 4. Relative abundance of caecal microbial taxa in rats fed a low-fat (LF) diet, a high-fat control (HFC) diet or the HFC diet supplemented with monobutyrin at $1 \mathrm{~g} / \mathrm{kg}$ diet (0.1 MB), MB at $5 \mathrm{~g} / \mathrm{kg}$ diet (MB) or tributyrin at $5 \mathrm{~g} / \mathrm{kg}$ diet (TB) for $21 \mathrm{~d}$ ( $n$ 5-7/group). (a) TM7 phylum; (b) unclassified genus, family F16; (c) Bacteroides genus; (d) unclassified genus, family S24-7; (e) Mucispirillum genus; ( $f$ ) Dorea genus; (g) rc4-4 genus. Values are means, with standard errors represented by vertical bars. Mean value was significantly different from that of the HFC group: ${ }^{\star} P<0.05,{ }^{\star \star} P<0.01$ (one-way ANOVA and Dunnett's test or Kruskall-Wallis test). 
(a)

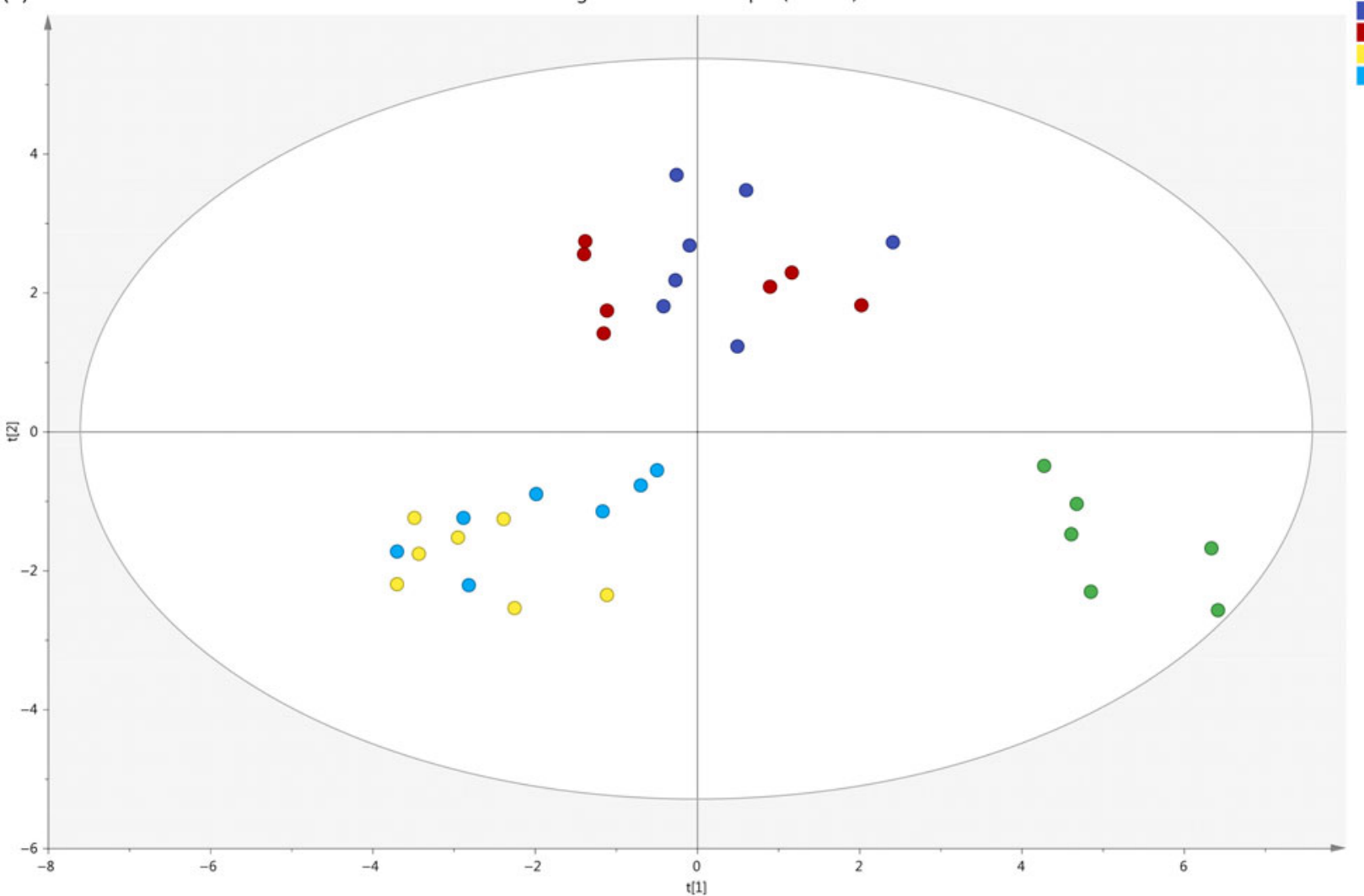

(b) Microbiota genus level $v$. liver lipid (PLS-DA)

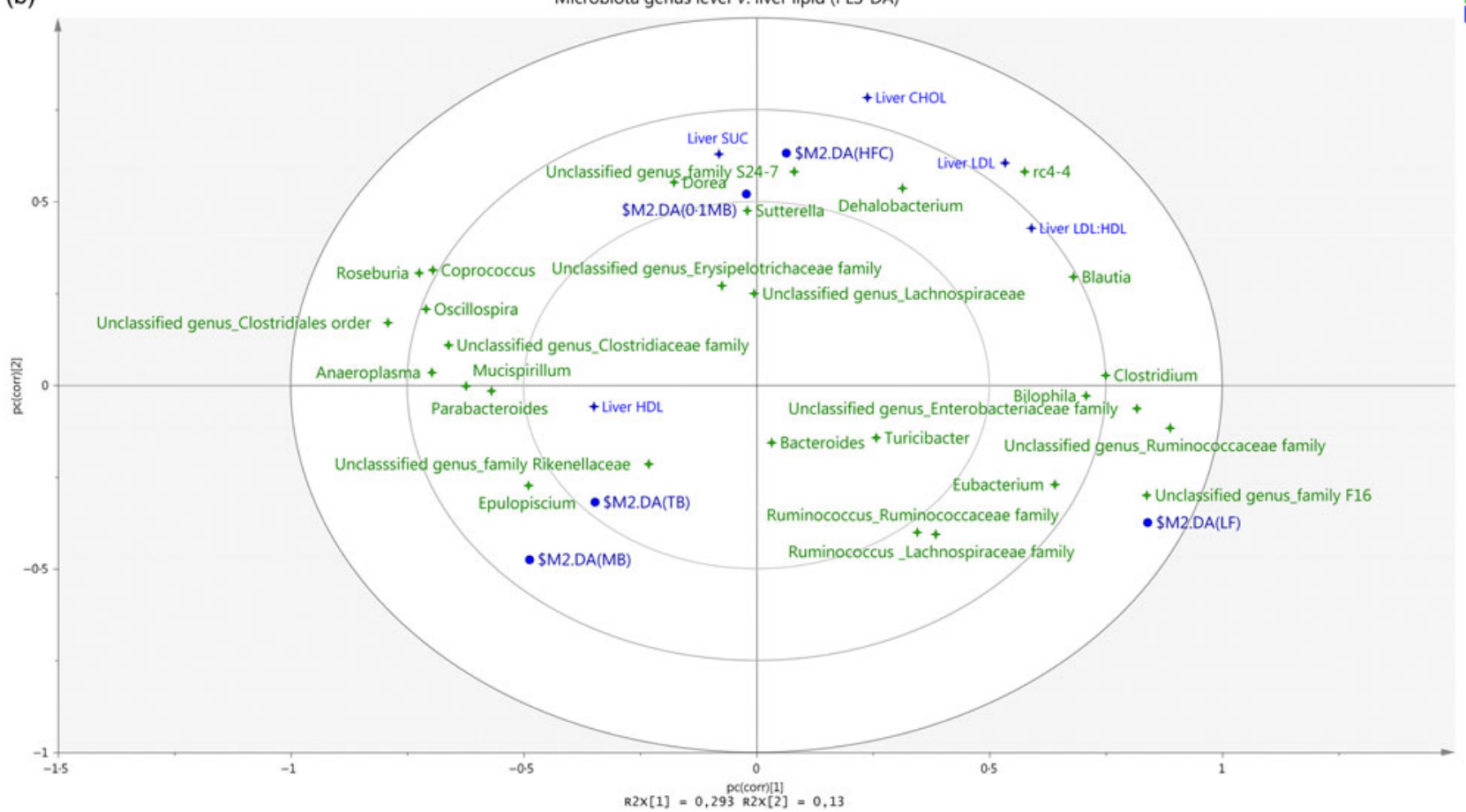

Fig. 5. (a) Score scatter plot representing how each group is separated and related to other groups: LF, low-fat diet; HFC, high-fat control diet; 0.1 MB, HFC diet supplemented with monobutyrin at $1 \mathrm{~g} / \mathrm{kg}$ diet; MB, HFC diet supplemented with monobutyrin at $5 \mathrm{~g} / \mathrm{kg}$ diet; TB, HFC diet supplemented with tributyrin at $5 \mathrm{~g} / \mathrm{kg}$ diet. PLS-DA, partial least-squares-projection-to-latent-structures-discriminant analysis. Each circle stands for one rat. (b) Loading scatter plot displays the caecal microbiota composition at the genus level and some liver lipid biomarkers in rats fed the LF diet, the HFC diet or the HFC diet supplemented with 0.1 MB, MB or TB for $21 \mathrm{~d}(n 5-7 /$ group). Variables are marked as four-point stars and groups are showed as circles. CHOL, cholesterol; SUC, succinic acid; X, microbiota genera; $\mathrm{Y}$, liver biomarkers. 
associated with mucosal injury), an inflammation-suppressing role has been indicated for Mucispirillum spp. due to an inverse relationship between its abundance and the expression of IL-12, an inflammatory cytokine ${ }^{(37)}$. The authors also mentioned that a direct effect of Mucispirillum on protecting animals from inflammatory disease should be experimentally tested. However, in the present study, no difference was seen in the concentration of LBP, a potential biomarker of inflammation, which is in contrast to other studies ${ }^{(2)}$. It may be questioned whether the 3-week feeding of the high-fat diet was long enough to induce a sufficiently high level of low-grade inflammation to be able to detect any anti-inflammatory properties of $\mathrm{MB}$ and TB. The higher abundance of Mucispirillum associated with butyrin feeding would indicate that supplementation of this ester in sufficient amounts could maintain the intestinal mucus layer from being disrupted by high-fat feeding. Notably, the abundance of Mucispirillum was even lower in the group fed the LF diet, indicating that this diet with its low content of substrate for the microbiota is provocative perse.

\section{Monobutyrin and tributyrin induce only minor changes in SCFA profile}

The caecal amounts of SCFA with the butyrin diets were lower than expected. Cellulose, added as a fibre component in all the diets, is relatively resistant to bacterial degradation, giving low amounts of SCFA. The SCFA formation with the HFC and LF diets was in concordance with previous studies using the same type of diets, as well as the decrease in SCFA and increase in succinic acid after high fat feeding $(8,32,38)$. However, it could be argued that butyric acid would be detected in higher amounts in the caecum of rats fed the butyrin diets. The reason for the low amounts of butyric acid could be that the butyrins were absorbed very quickly in the caecum of rats or perhaps already in the upper part of the gut. In line with this explanation, it has been shown that TAG are rapidly hydrolysed by gastric ${ }^{(39)}$ and pancreatic lipase ${ }^{(40)}$, and readily absorbed into the digestive mucosa in hydrolysed or esterified form. Indeed, MB has been shown to be hydrolysed rapidly in vitro by water-soluble enzymes (hydrolases and esterases) found in both plasma and tissues ${ }^{(41)}$, and TB is also hydrolysed quickly to butyric acid by esterases/ lipases in blood samples, reaching a peak concentration (about $2 \cdot 2 \mu \mathrm{M})$ at $25 \mathrm{~min}$ after oral administration of $2 \mathrm{~g} / \mathrm{kg} \mathrm{TB}^{(42,43)}$. On the other hand, in a study, by Augustin et al. ${ }^{(44)}$, the radiolabelled TB was found in the caecum and colon of rats, although in lesser amounts than in the small-intestinal walls. However, to our knowledge there are no in vivo studies in the literature on the measurement of $\mathrm{MB}$ in the gastrointestinal tract. Studies in vitro, simulating gastrointestinal conditions, have shown that TB is degraded to MB which survives gastrointestinal conditions ( $\mathrm{K}$ Schwarzer and J Björk, published conference paper). The pronounced effects on caecal microbiota composition in the present study also indicate that the butyrins are affecting the colonic substrate in some way, e.g. via the bile acids. It is also important to mention that there are effects on SCFA with MB and TB in the caecum, serum and liver. Since metabolic cross-feeding exists between the SCFA, the measurements may be complicated in a starving environment $^{(6)}$. Thus, it should be considered that instead of using dietary fibre, which is known to increase SCFA formation, the test diets were supplemented with glycerol esters of SCFA, possibly resulting in different SCFA profiles compared with other studies. It is also important to emphasise that the portal butyric acid concentrations tended to be higher in the MB and TB groups than in the HFC group, which may have reached significance at a higher dose or longer exposure.

Monobutyrin and tributyrin affect liver cholesterol and hepatic gene expression of bile acid enzymes

There was a considerable cholesterol-lowering effect especially by MB, but also by TB. It has been already reported that TB partly decreases serum concentrations of cholesterol and TAG, accompanied with a significant reduction in hepatic TAG accumulation in high fat-fed mice ${ }^{(45)}$. In the liver, cholesterol is used to generate bile acids, which, in turn, are secreted into the small intestine, stimulating lipid absorption, including cholesterol ${ }^{(46)}$. The bile acid synthetic pathway is facilitated by Cyp7a1, which usually accounts for the pool size of bile acids, followed by the activity of Cyp $8 b 1$ that determines the composition of bile acids. The expression of Cyp7a1 and Cyp8b1 was lower in the MB and TB groups, with greater reduced expression of Cyp $8 b 1$ in the $\mathrm{MB}$ group, associated with a concomitant decrease in liver cholesterol. As bile acids are necessary for lipid absorption, this finding indicates that the cholesterol-lowering effect could be due to reduced absorption or increased excretion of cholesterol in the intestine, leaving less cholesterol transported back to the liver. In the same manner, it has been reported that cholesterol absorption was reduced, while faecal neutral sterol excretion was increased in Cyp7a1-deficient mice ${ }^{(47)}$. Although contributing to minor changes, it should be mentioned that SCFA, especially butyric acid, may take part in cholesterol metabolism because butyrate has been shown to directly inhibit intestinal lipid transport ${ }^{(48)}$.

Liver succinic acid levels are reduced with monobutyrin and tributyrin

The decrease in liver succinic acid, and also the tendency to a decreased succinic acid:butyric acid ratio, observed with $\mathrm{MB}$ and TB indicates that this supplementation is attributed to protective effects against high-fat feeding. Succinic acid is traditionally known as a substrate for microbial synthesis of propionate and does not substantially accumulate in the large bowel $^{(6)}$. The amounts of succinic acid in the liver were positively related to the caecal amounts of propionic acid and also to those in serum (but not to those in the liver) and the amount of liver cholesterol. Likewise, succinic acid concentration can be increased at the expense of butyric acid in the caecum of rats fed high-fat diets and in human subjects having depressed microbial activity in the colon due to treatment with broad-spectrum antibiotics, indicating its harmful effect over time ${ }^{(8,49)}$. A number of physiological effects have been 
connected to succinate and it has been shown to promote Clostridium difficile infection in human subjects ${ }^{(9,49)}$. Furthermore, elevated succinate in urine and plasma has been reported in animals subjected to metabolic and diabetic disease models, including hypertension ${ }^{(50,51)}$. Succinic acid has also been recognised as an LPS-induced inflammatory signal that enhances the production of the inflammatory protein IL-1 $\beta$ in dendritic cells and macrophages ${ }^{(52,53)}$. On the other hand, in a recent study succinic acid, but also propionic acid, was demonstrated to be a substrate of intestinal gluconeogenesis and as a consequence had the capacity to improve glucose homeostasis ${ }^{(54)}$. The observed association between succinic acid and liver cholesterol in this study can be considered as an interesting finding, since succinate has been claimed to increase blood pressure in animals via activation of its receptor GPR91 ${ }^{(55)}$, potentially supporting its role in hypertension-related diseases such as atherosclerosis. Due to its activation on the transcriptional factor hypoxia-inducible factor $1 \alpha$ in both tumours and inflammatory states, succinic acid has been proposed as a signal linking inflammation and cancer ${ }^{(52,56,57)}$. Thus, the role of succinic acid in health and disease states needs further investigation.

\section{Low-fat diet}

The group fed the LF diet had some unexpected results, for example final body weight and body weight gain. This could be due to lower energy content of the LF diet, which was compensated by a higher feed intake to maintain different physiological requirements. Furthermore, when taking the feed intake into account together with the weight gain, feed efficiency ratio was similar between all groups, although it could be expected to be even lower due to the lower energy density of the LF diet. The activity of the rats in different groups may also differ, but no behavioural test was performed and we do not know if the LF group was less active than the other groups or not.

Concerning the SCFA, it can be discussed if a LF diet containing cellulose, which is almost resistant to fermentation, is an optimal control and a description of a normal state for SCFA and thus also the microbiota. It might be better to compare only the high-fat diets. Perhaps it would be more relevant to include a positive control, containing fermentable fibres that are associated with high formation of SCFA. The lack of fermentable fibre and also fat, that indirectly can be a substrate for the microbiota via the bile acids, may be provocative by itself, creating a starving environment in the colon. Such a diet also leads to a high intake of digestible starch, which may change the appetite hormonal profiles resulted in a higher food intake ${ }^{(58)}$.

The LF reference group used in the study, on the other hand, seems to be appropriate concerning results on lipids. Furthermore, the caecal SCFA was higher and liver succinic acid lower with this group than with the HFC group, which is consistent with other studies.

In conclusion, the results from the present study suggest that supplementation of $5 \mathrm{~g} / \mathrm{kg}$ of MB and TB into a HFC diet is effective in decreasing liver cholesterol concentration in rats after 3 weeks. This could not clearly be related to any specific SCFA since these were similar whether the butyrins were added or not. Indeed, we observed a down-regulation of hepatic bile acid synthesis genes and a decreased hepatic concentration of succinic acid. However, the mechanisms behind the effects of MB and TB on liver cholesterol need further investigation. The present study also highlights a new role of TB in lipid metabolism, particularly in reduction of liver cholesterol associated with a high-fat diet, and also introduces $\mathrm{MB}$ as a promising candidate with similar effects.

\section{Supplementary material}

The supplementary material for this article can be found at https://doi.org/10.1017/jns.2017.54

\section{Acknowledgements}

We would like to thank Alf Gunnarsson and Stefan Lundmark for informative discussions. We thank Robert Zuban for assistance in multivariate analyses. Perstorp AB contributed with the glycerol esters.

This work was supported by the Mekong 1000 Scholarship, Viet Nam and Perstorp AB.

M. N., F. F. H. and T. D. N. conceived and designed the study. T. D. N. performed the study, most of the analyses and evaluated the results. O. P. and F. F. H. performed and evaluated the microbiota analyses. All authors took part in writing the manuscript and read and approved the final version of the manuscript.

F. F. H. is a shareholder in ProPrev AB. M. N., O. P. and T. D. N. have declared no conflict of interests.

\section{References}

1. Krajmalnik-Brown R, Ilhan ZE, Kang DW, et al. (2012) Effects of gut microbes on nutrient absorption and energy regulation. Nutr Clin Pract 27, 201-214.

2. Cani PD, Amar J, Iglesias MA, et al. (2007) Metabolic endotoxemia initiates obesity and insulin resistance. Diabetes 56, 1761-1772.

3. Graham C, Mullen A \& Whelan K (2015) Obesity and the gastrointestinal microbiota: a review of associations and mechanisms. Nutr Rev 73, 376-385.

4. Sun L, Yu Z, Ye X, et al. (2010) A marker of endotoxemia is associated with obesity and related metabolic disorders in apparently healthy Chinese. Diabetes Care 33, 1925-1932.

5. Munford RS (2005) Detoxifying endotoxin: time, place and person. $J$ Endotoxin Res 11, 69-84.

6. Macfarlane S \& Macfarlane GT (2003) Regulation of short-chain fatty acid production. Proc Nutr Soc 62, 67-72.

7. Zhong YD, Teixeira C, Marungruang N, et al. (2015) Barley malt increases hindgut and portal butyric acid, modulates gene expression of gut tight junction proteins and Toll-like receptors in rats fed high-fat diets, but high advanced glycation end-products partially attenuate the effects. Food Funct 6, 3165-3176.

8. Jakobsdottir G, Xu J, Molin G, et al. (2013) High-fat diet reduces the formation of butyrate, but increases succinate, inflammation, liver fat and cholesterol in rats, while dietary fibre counteracts these effects. PLOS ONE 8, e80476.

9. Berggren AM (1996) Formation, pattern and physiological effects of short-chain fatty acids. PhD Thesis, Institute of Technology, Lund University, Sweden.

10. Setoyama H, Imaoka A, Ishikawa H, et al. (2003) Prevention of gut inflammation by Bifidobacterium in dextran sulfate-treated 
gnotobiotic mice associated with Bacteroides strains isolated from ulcerative colitis patients. Microbes Infect 5, 115-122.

11. Macfarlane GT \& Macfarlane S (2012) Bacteria, colonic fermentation, and gastrointestinal health. $J A O A C$ Int 95, 50-60.

12. Ni YF, Wang J, Yan XL, et al. (2010) Histone deacetylase inhibitor, butyrate, attenuates lipopolysaccharide-induced acute lung injury in mice. Respir Res 11, 33.

13. Segain JP, de la Bletiere DR, Bourreille A, et al. (2000) Butyrate inhibits inflammatory responses through NFKB inhibition: implications for Crohn's disease. Gut 47, 397-403.

14. Clarke JM, Topping DL, Bird AR, et al. (2008) Effects of highamylose maize starch and butyrylated high-amylose maize starch on azoxymethane-induced intestinal cancer in rats. Carcinogenesis 29, 2190-2194.

15. Furusawa Y, Obata Y, Fukuda S, et al. (2013) Commensal microbederived butyrate induces the differentiation of colonic regulatory $\mathrm{T}$ cells. Nature 504, 446-450.

16. Humphreys KJ, Conlon MA, Young GP, et al. (2014) Dietary manipulation of oncogenic microRNA expression in human rectal mucosa: a randomized trial. Cancer Prev Res (Pbila) 7, 786-795.

17. Le Leu RK, Scherer BL, Mano MT, et al. (2016) Dietary butyrylated high-amylose starch reduces azoxymethane-induced colonic $O^{6}$ methylguanine adducts in rats as measured by immunohistochemistry and high-pressure liquid chromatography. Nutr Res 36, 982-988.

18. Vinolo MA, Rodrigues HG, Hatanaka E, et al. (2011) Suppressive effect of short-chain fatty acids on production of proinflammatory mediators by neutrophils. J Nutr Biochem 22, 849-855.

19. Clarke KO, Feinman R \& Harrison LE (2001) Tributyrin, an oral butyrate analogue, induces apoptosis through the activation of caspase-3. Cancer Lett 171, 57-65.

20. Heidor R, Furtado KS, Ortega JF, et al. (2014) The chemopreventive activity of the histone deacetylase inhibitor tributyrin in colon carcinogenesis involves the induction of apoptosis and reduction of DNA damage. Toxicol Appl Pharmacol 276, 129-135.

21. Kuroiwa-Trzmielina J, de Conti A, Scolastici C, et al. (2009) Chemoprevention of rat hepatocarcinogenesis with histone deacetylase inhibitors: efficacy of tributyrin, a butyric acid prodrug. Int J Cancer 124, 2520-2527.

22. Heidor R, de Conti A, Ortega JF, et al. (2016) The chemopreventive activity of butyrate-containing structured lipids in experimental rat hepatocarcinogenesis. Mol Nutr Food Res 60, 420-429.

23. Berggren AM, Björck IME, Nyman EMGL, et al. (1993) Short-chain fatty-acid content and $\mathrm{pH}$ in cecum of rats given various sources of carbohydrates. J Sci Food Agric 63, 397-406.

24. Bjorck I, Nyman M, Pedersen B, et al. (1987) Formation of enzyme resistant starch during autoclaving of wheat-starch - studies in vitro and in vivo. J Cereal Sci 6, 159-172.

25. Leonel AJ, Teixeira LG, Oliveira RP, et al. (2013) Antioxidative and immunomodulatory effects of tributyrin supplementation on experimental colitis. Br J Nutr 109, 1396-1407.

26. Zhao GH, Nyman M \& Jonsson JA (2006) Rapid determination of short-chain fatty acids in colonic contents and faeces of humans and rats by acidified water-extraction and direct-injection gas chromatography. Biomed Chromatogr 20, 674-682.

27. Zhao GH, Liu JF, Nyman M, et al. (2007) Determination of shortchain fatty acids in serum by hollow fiber supported liquid membrane extraction coupled with gas chromatography. J Chromatogr $B$ 846, 202-208.

28. Hara A \& Radin NS (1978) Lipid extraction of tissues with a lowtoxicity solvent. Anal Biochem 90, 420-426.

29. Jakobsdottir G, Jadert C, Holm L, et al. (2013) Propionic and butyric acids, formed in the caecum of rats fed highly fermentable dietary fibre, are reflected in portal and aortic serum. Br J Nutr 110, 1565-1572.

30. Kuehbacher T, Rehman A, Lepage P, et al. (2008) Intestinal TM7 bacterial phylogenies in active inflammatory bowel disease. $J$ Med Microbiol 57, 1569-1576.

31. Brinig MM, Lepp PW, Ouverney CC, et al. (2003) Prevalence of bacteria of division TM7 in human subgingival plaque and their association with disease. Appl Environ Microbiol 69, 1687-1694.
32. Zhong Y, Nyman M \& Fak F (2015) Modulation of gut microbiota in rats fed high-fat diets by processing whole-grain barley to barley malt. Mol Nutr Food Res 59, 2066-2076.

33. Chen D, Yang Z, Chen X, et al. (2014) The effect of Lactobacillus rhamnosus hsryfm 1301 on the intestinal microbiota of a hyperlipidemic rat model. BMC Complement Altern Med 14, 386.

34. Wang Y, Ames NP, Tun HM, et al. (2016) High molecular weight barley $\beta$-glucan alters gut microbiota toward reduced cardiovascular disease risk. Front Microbiol 7, 129.

35. Robertson BR, O'Rourke JL, Neilan BA, et al. (2005) Mucispirillum schaedleri gen. nov., sp. nov., a spiral-shaped bacterium colonizing the mucus laver of the gastrointestinal tract of laboratory rodents. Int J Syst Evol Microbiol 55, 1199-1204.

36. Belzer C, Gerber GK, Roeselers G, et al. (2014) Dynamics of the microbiota in response to host infection. PLOS ONE 9, e95534.

37. Liu J, Xu T, Zhu W, et al. (2014) High-grain feeding alters caecal bacterial microbiota composition and fermentation and results in caecal mucosal injury in goats. Br J Nutr 112, 416-427.

38. Zhong Y, Marungruang N, Fak F, et al. (2015) Effects of two whole-grain barley varieties on caecal SCFA, gut microbiota and plasma inflammatory markers in rats consuming low- and high-fat diets. Br J Nutr 113, 1558-1570.

39. Gargouri Y, Pieroni G, Riviere C, et al. (1986) Kinetic assay of human gastric lipase on short- and long-chain triacylglycerol emulsions. Gastroenterology 91, 919-925.

40. Lairon D, Nalbone G, Lafont H, et al. (1980) Effect of bile lipids on the adsorption and activity of pancreatic lipase on triacylglycerol emulsions. Biochim Biophys Acta 618, 119-128.

41. Deuel HJ Jr (1955) The digestion and absorption of fats in the gastrointestinal tract. In Lipids: Their Chemistry and Biochemistry, vol. II, Biochemistry (Digestion, Absorption, Transport and Storage), pp. 3194. New York: Interscience.

42. Su J, Zhang N \& Ho PC (2004) Determination of tributyrin and its metabolite butyrate in Wistar rat plasma samples by gas chromatography/mass spectrometry. Rapid Commun Mass Spectrom 18, 2217 2222.

43. Egorin MJ, Yuan ZM, Sentz DL, et al. (1999) Plasma pharmacokinetics of butyrate after intravenous administration of sodium butyrate or oral administration of tributyrin or sodium butyrate to mice and rats. Cancer Chemother Pharmacol 43, 445-453.

44. Augustin MA, Abeywardena MY, Patten G, et al. (2011) Effects of microencapsulation on the gastrointestinal transit and tissue distribution of a bioactive mixture of fish oil, tributyrin and resveratrol. $J$ Funct Foods 3, 25-37.

45. Vinolo MA, Rodrigues HG, Festuccia WT, et al. (2012) Tributyrin attenuates obesity-associated inflammation and insulin resistance in high-fat-fed mice. Am J Physiol Endocrinol Metab 303, E272-E282.

46. Lefebvre P, Cariou B, Lien F, et al. (2009) Role of bile acids and bile acid receptors in metabolic regulation. Physiol Rev 89, 147-191.

47. Jones RD, Lopez AM, Tong EY, et al. (2015) Impact of physiological levels of chenodeoxycholic acid supplementation on intestinal and hepatic bile acid and cholesterol metabolism in Cyp7a1-deficient mice. Steroids 93, 87-95.

48. Marcil V, Delvin E, Garofalo C, et al. (2003) Butyrate impairs lipid transport by inhibiting microsomal triglyceride transfer protein in Caco-2 cells. J Nutr 133, 2180-2183.

49. Ferreyra JA, Wu KJ, Hryckowian AJ, et al. (2014) Gut microbiotaproduced succinate promotes $C$. difficile infection after antibiotic treatment or motility disturbance. Cell Host Microbe 16, 770-777.

50. Toma I, Kang JJ, Sipos A, et al. (2008) Succinate receptor GPR91 provides a direct link between high glucose levels and renin release in murine and rabbit kidney. J Clin Invest 118, 2526-2534.

51. Sadagopan N, Li W, Roberds SL, et al. (2007) Circulating succinate is elevated in rodent models of hypertension and metabolic disease. Am J Hypertens 20, 1209-1215.

52. Tannahill GM, Curtis AM, Adamik J, et al. (2013) Succinate is an inflammatory signal that induces IL-1 $\beta$ through HIF-1 $\alpha$. Nature 496, 238-242. 
53. Rubic T, Lametschwandtner G, Jost S, et al. (2008) Triggering the succinate receptor GPR91 on dendritic cells enhances immunity. Nat Immunol 9, 1261-1269.

54. De Vadder F, Kovatcheva-Datchary P, Zitoun C, et al. (2016) Microbiota-produced succinate improves glucose homeostasis via intestinal gluconeogenesis. Cell Metab 24, 151-157.

55. He W, Miao FJ, Lin DC, et al. (2004) Citric acid cycle intermediates as ligands for orphan G-protein-coupled receptors. Nature 429, 188-193.
56. Selak MA, Armour SM, MacKenzie ED, et al. (2005) Succinate links TCA cycle dysfunction to oncogenesis by inhibiting HIF- $\alpha$ prolyl hydroxylase. Cancer Cell 7, 77-85.

57. Pistollato F, Abbadi S, Rampazzo E, et al. (2010) Hypoxia and succinate antagonize 2-deoxyglucose effects on glioblastoma. Biochem Pharmacol 80, 1517-1527.

58. Aller EE, Abete I, Astrup A, et al. (2011) Starches, sugars and obesity. Nutrients 3, 341-369. 